\title{
Correction to: High-Rise Urban Form and Microclimate
}

\section{Correction to:}

F. Yang and L. Chen, High-Rise Urban Form

and Microclimate, The Urban Book Series, https://doi.org/10.1007/978-981-15-1714-3

The original version of the book was inadvertently published with the below-mentioned errors:

1. incorrect funder information in the copyright page;

2. incorrect placement of texts related to Fig. 4.6, Fig. 4.9 and Fig. 4.12; and

3. incorrect background pattern in Fig. 5.5 and Fig. 5.13.

The corrected chapter and book have been updated with the changes.

The updated version of the book can be found at https://doi.org/10.1007/978-981-15-1714-3_4

https://doi.org/10.1007/978-981-15-1714-3_5

https://doi.org/10.1007/978-981-15-1714-3

(C) Springer Nature Singapore Pte Ltd. 2020

F. Yang and L. Chen, High-Rise Urban Form and Microclimate,

The Urban Book Series, https://doi.org/10.1007/978-981-15-1714-3_9 